\title{
Cause and risk of catastrophic eruptions in the Japanese Archipelago
}

\author{
By Yoshiyuki Tatsumi*1,*2,† and Keiko SuZUKI-Kamata*1
}

(Communicated by Izumi YoKOYAMA, M.J.A.)

\begin{abstract}
The Japanese Archipelago is characterized by active volcanism with variable eruption styles. The magnitude $(M)$-frequency relationships of catastrophic caldera-forming eruptions $(M \geq 7)$ are statistically different from those of smaller eruptions $(M \leq 5.7)$, suggesting that different mechanisms control these eruptions. We also find that volcanoes prone to catastrophic eruptions are located in regions of low crustal strain rate $\left(<0.5 \times 10^{8} / \mathrm{y}\right)$ and propose, as one possible mechanism, that the viscous silicic melts that cause such eruptions can be readily segregated from the partially molten lower crust and form a large magma reservoir in such a tectonic regime. Finally we show that there is a $\sim 1 \%$ probability of a catastrophic eruption in the next 100 years based on the eruption records for the last $120 \mathrm{ky}$. More than 110 million people live in an area at risk of being covered by tephra $>20 \mathrm{~cm}$ thick, which would severely disrupt every day life, from such an eruption on Kyushu Island, SW Japan.
\end{abstract} hazards

Keywords: catastrophic eruptions, caldera formation, large magma reservoir, strain rate,

\section{Introduction}

The Japanese Archipelago is built at convergent plate boundaries where oceanic plates are being subducted at trenches and is characterized by active volcanism with variable eruption styles. Even though catastrophic caldera-forming eruptions that produce more than $100 \mathrm{~km}^{3}$ of tephra are rare in Japan $(<0.01 \%$ in the frequency) they overwhelm smaller events in total erupted volume $(>60 \%)$. Once such a catastrophic eruption occurs, it should have significant societal and environmental impacts. Understanding the cause of catastrophic eruptions is thus of primary importance for those living in volcano countries like Japan. However, the mechanisms that trigger these eruptions are elusive since the processes occurring in 'normal' volcanic systems cannot simply be scaled up to much larger magma reservoirs beneath calderas. Herein we analyze statistically the size and frequency of volcanic eruptions in Japan and

\footnotetext{
*1 Department of Earth and Planetary Sciences, Kobe University, Kobe, Hyogo, Japan.

*2 Research and Development Center for Ocean Drilling Science, Japan Agency for Marine-Earth Science and Technology, Yokosuka, Kanagawa, Japan.

$\dagger$ Correspondence should be addressed: Y. Tatsumi, Department of Earth and Planetary Sciences, Kobe University, Rokkodai 1-1, Nada-ku, Kobe, Hyogo 657-8504, Japan (e-mail: tatsumi@ diamond.kobe-u.ac.jp).
}

discuss the mechanisms of catastrophic calderaforming eruptions. We also evaluate the risks of such an eruption based on the geological record of a caldera-forming eruption that occurred at $\sim 28 \mathrm{ka}$ in Japan.

\section{Statistical analyses of volcanic eruption}

The magnitude-frequency $(M-F)$ relationships of volcanic eruptions provide a key to estimating the eruption frequency and help to assess associated hazards and risks. An inverse correlation between $M$ and $F$ is well known (Fig. 1a) and can be described by (ref. 1):

$$
\log _{10} F=3.05-0.86 M
$$

where

$$
\begin{aligned}
M & =\log _{10}[\text { mass erupted }(\mathrm{kg})]-7 \\
F & =\text { the frequency of eruptions with } M \\
& =p(\text { an integer }) .
\end{aligned}
$$

However, simple extrapolation of this relationship from small to large eruptions is not valid, and eruptions with $M \geq 9$ have been extremely rare on this planet (Fig. 1a). The reason for this is that the volcanic eruption mechanism depends strongly on the scale of the system. ${ }^{2)}$ The scale and structure of volcanic systems that cause catastrophic eruptions depend on the tectonic regime, with those in 

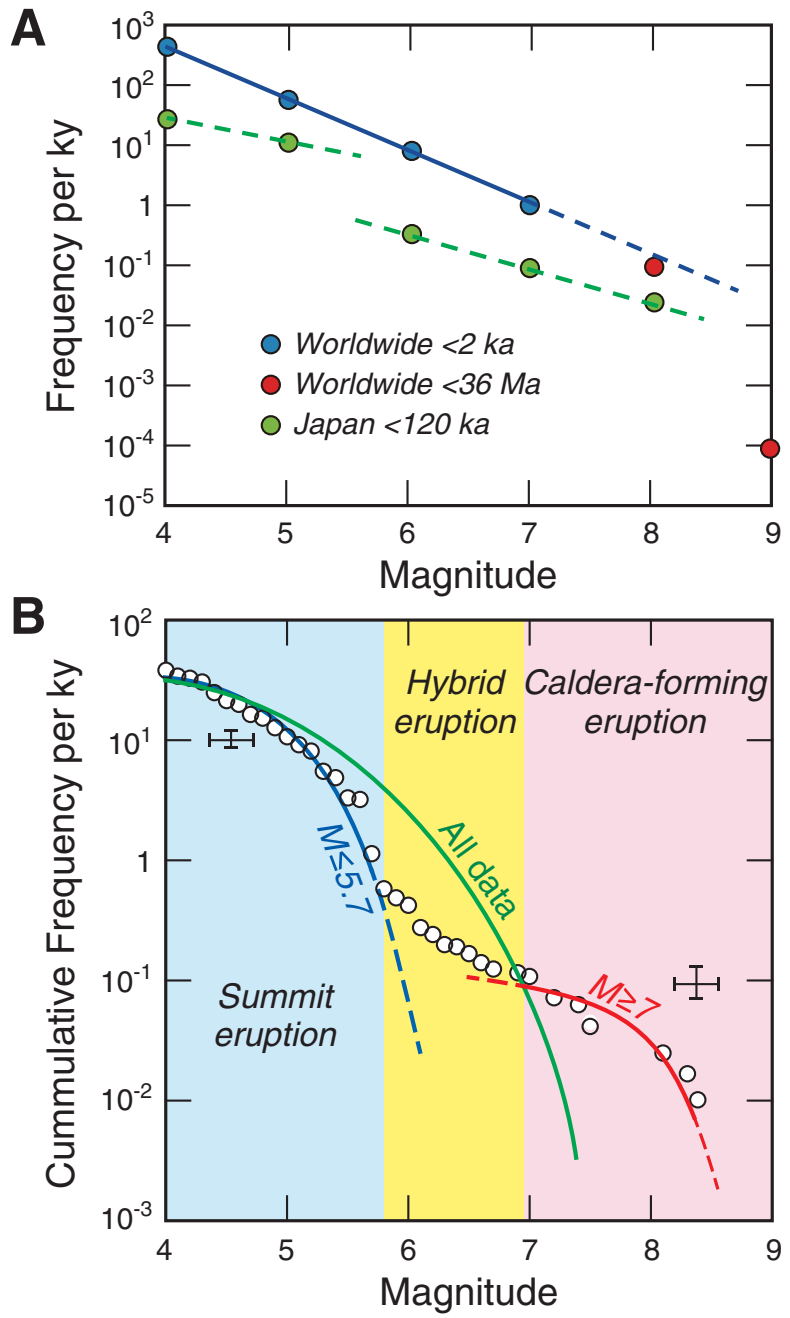

Fig. 1. The magnitude-frequency $(M-F)$ relationships of volcanic eruptions. (A). Although an inverse correlation between $M$ and $F$ is well known for volcanic eruptions worldwide, the relationships among Japanese eruptions are not simple and form two lineations. (B). The $M-F$ relationships for Japanese eruptions $(<120 \mathrm{ka})$. The overall relationship cannot be described by a single set of parameters. Instead, summit eruptions $(M \leq 5.7)$ and caldera-forming eruptions $(M \geq 7)$ are reproduced by separate Weibull parameters, suggesting that different mechanisms control the two eruption styles. The typical errors in magnitude and frequency are shown by error bars.

subduction zones, such as Japan, different from those in other tectonic settings, such as hotspots (e.g., Yellowstone $^{3)}$ ) and regional transtensional zones (e.g., Long Valley $\left.{ }^{4}\right)$. Indeed, the $M-F$ relationship for events in the Japan arcs (for events < $120 \mathrm{ka}$; ref. 5) is not as simple as that for other eruptions elsewhere with similar amplitudes and defines two discrete lineations (Fig. 1a). Careful examination of the $M-F$ relationship is thus needed to reveal the exact nature of catastrophic eruptions in Japan.

The $M-F$ relationship that characterizes common eruptions must eventually break down at the extremes of the distributions, as there are physical limits to the size of eruptions. ${ }^{2)}$ To make a quantitative assessment of the size and frequency of volcanic eruptions in these regions, the extreme value theory has to be applied. ${ }^{2), 6)}$ The Weibull function is the part of this theory that can be used for the upper limit of size ${ }^{7)}$ where the probability density function of amplitude $S$ and the corresponding cumulative distribution function (fraction of amplitudes that are equal to or greater than $S$ ) are given by:

$$
p(S)=\frac{\beta}{\tau}\left(\frac{S}{\tau}\right)^{\beta-1} \exp \left[-\left(\frac{S}{\tau}\right)^{\beta}\right]
$$

and

$$
P(S)=\exp \left[-\left(\frac{S}{\tau}\right)^{\beta}\right]
$$

respectively, where $\beta$ and $\tau$ are fitting parameters. In the case of volcanic eruptions, the relative frequency $F(M)$ of eruptions with magnitudes over $M$ is then described by:

$$
F(M)=\exp \left(-a M^{b}\right)
$$

where $a>0, b>1$ (ref. 2).

The $M-F$ relationship for eruptions $<120 \mathrm{ka}$ and with $M \geq 4$ ( $M$ given to one decimal place) in the Japanese $\operatorname{arcs}^{5)}$ (447 events in total) is analysed using the Weibull function in Fig. 1b. The overall relationship exhibits three inflections and cannot be reproduced by a single set of Weibull parameters. Instead, the relationship requires two sets of Weibull parameters, one for eruptions with $M \leq 5.7(a=2.81 \times$ $\left.10^{-7}, b=9.44\right)$ and the other for eruptions with $M \geq 7\left(a=1.55 \times 10^{-13}, \quad b=14.4\right)$; eruptions with $5.7<M<7$ can be expressed by the sum of above two functions. These magnitude thresholds correspond to changes in eruption style, with eruptions of $M \leq 5.7$ characterised by summit eruptions, and all eruptions with $M \geq 7$ catastrophic caldera-forming eruptions; events with intermediate $M$ are hybrid eruptions including both eruption styles. Based on the Weibull parameters obtained here, the practical limit of the magnitude for normal summit eruptions is 6.9 for which the frequency falls to less than one event over $15 \mathrm{my}$, an elapsed time for the current tectonic setting around Japan. Thus the two eruption styles, summit eruptions and caldera-forming eruptions, reflect different mechanisms. 
Two different mechanisms may operate even in a single volcano, as summit eruptions certainly took place at a volcano that caused catastrophic calderaforming eruptions. The reason for these mechanism changes should be understood based on temporal variations in eruptive style, magma compositions, tectonic regime and so on for a single volcano. Such variations, however, have not been well documented at the present stage. We thus simply divide Japanese volcanoes into two groups, one solely with summit eruptions and the other with catastrophic eruptions and shall discuss the cause of operation of two different mechanisms for these two groups.

\section{Mechanism of catastrophic caldera-forming eruptions}

Over-pressurization of a magmatic reservoir generated by injection of magma is an essential trigger for relatively small eruptions, ${ }^{8), 9)}$ in which the overpressure is proportional to the viscosity of the surrounding crust and the magma flux during a single recharge event, and inversely proportional to the volume of the reservoir. Injection of high-temperature magma into the reservoir may further heat the residing magma reducing the water solubility in that magma. Oversaturation of water and bubble growth in the magma in the reservoir may induce further overpressure and trigger an eruption. We suggest that this mechanism drives summit eruptions at Japanese volcanoes.

A catastrophic eruption discharges voluminous magmas from a large magma reservoir, causing the roof to collapse forming a caldera. Recent numerical and experimental approaches ${ }^{9), 10)}$ show that silicic magma buoyancy in a large and rather flat magma reservoir can subject the roof to overpressures greater than the critical overpressure required for dyke propagation. This mechanism may further provide a qualitative explanation for the observation that the largest eruptions are rarer than smaller eruptions ${ }^{9)}$ (Fig. 1a). Thus, catastrophic caldera-forming eruptions in Japan could be triggered by melt buoyancy within large silicic magma reservoirs.

However, herein lies a problem: what controls whether a large silicic magma reservoir or a smaller reservoir that gives rise to a summit eruption forms? Partial melting of the lower crust caused by heat derived from basalt magmas and/or high-temperature mantle is widely accepted as a common mechanism to generate silicic magmas. ${ }^{11), 12)}$ Indeed, crust-derived silicic magmas play a key role in magmatism in the NE Japan arc: they erupt directly as tholeiitic magmas or act as an end-member component in the mixing that generates calc-alkaline magmas. ${ }^{13), 14)}$ However, in the last $120 \mathrm{ky}$ there has been only two semi-catastrophic caldera-forming eruptions at Towada volcano $(M=6.7)$ in the NE Japan arc, with most active volcanoes associated with summit eruptions (Fig. 2). Although silicic magmas are generally produced by crustal melting in this arc, these magmas tend not to form a large magma reservoir but to form a smaller reservoir.

To build a shallow-level large silicic magma reservoir, effective and continuous extraction of highly viscous silicic melts from the partially molten zone in the lower crust is required, otherwise partial melts evolve to intermediate and finally basaltic compositions as a result of a continuous heat supply. These high-degree, crust-derived partial melts are the source of tholeiitic andesites and basalts that cause summit eruptions at volcanoes in the NE Japan arc. ${ }^{13)}$ The factors that control whether melts segregate from the lower crust are the amount of partial melt, the viscosity and density contrast between melts and the residual solids, the applied stress pattern, and the strain rate. The first two factors, however, are not well constrained. We may thus have to assume an identical lower crust composition and constant heat supply as a first step. The highest density of volcanoes in arc settings occurs along the volcanic front; the boundary between the volcanic arc and the non-volcanic forearc (Fig. 2). The volcanic front is generally under compression $^{15)}$ and both caldera-forming and summit eruptions occur (Fig. 2). This suggests that the stress regime may not be a critical factor in controlling eruption style. Instead, we here focus on the strain rate as an important factor controlling the formation of large silicic magma reservoirs. Analysing the strain rates of active faults, Japan can be divided into two regions (Fig. 2): one with relatively high strain rates $\left(>0.5 \times 10^{8} / \mathrm{y}\right)$, the other with relatively low strain rates. ${ }^{16)}$ Catastrophic caldera-forming eruptions have not taken place in the region with high strain rates. Instead, under tectonics with low strains rates the effective viscosity contrast between the melt and the solid is larger, developing instabilities that induce low-degree silicic partial melts to segregate, consistent with experimental and numerical analyses of partially molten rocks. ${ }^{17}$ )

\section{Risks of catastrophic eruptions}

Our statistical analyses of the frequency of catastrophic eruptions using the Weibull function 


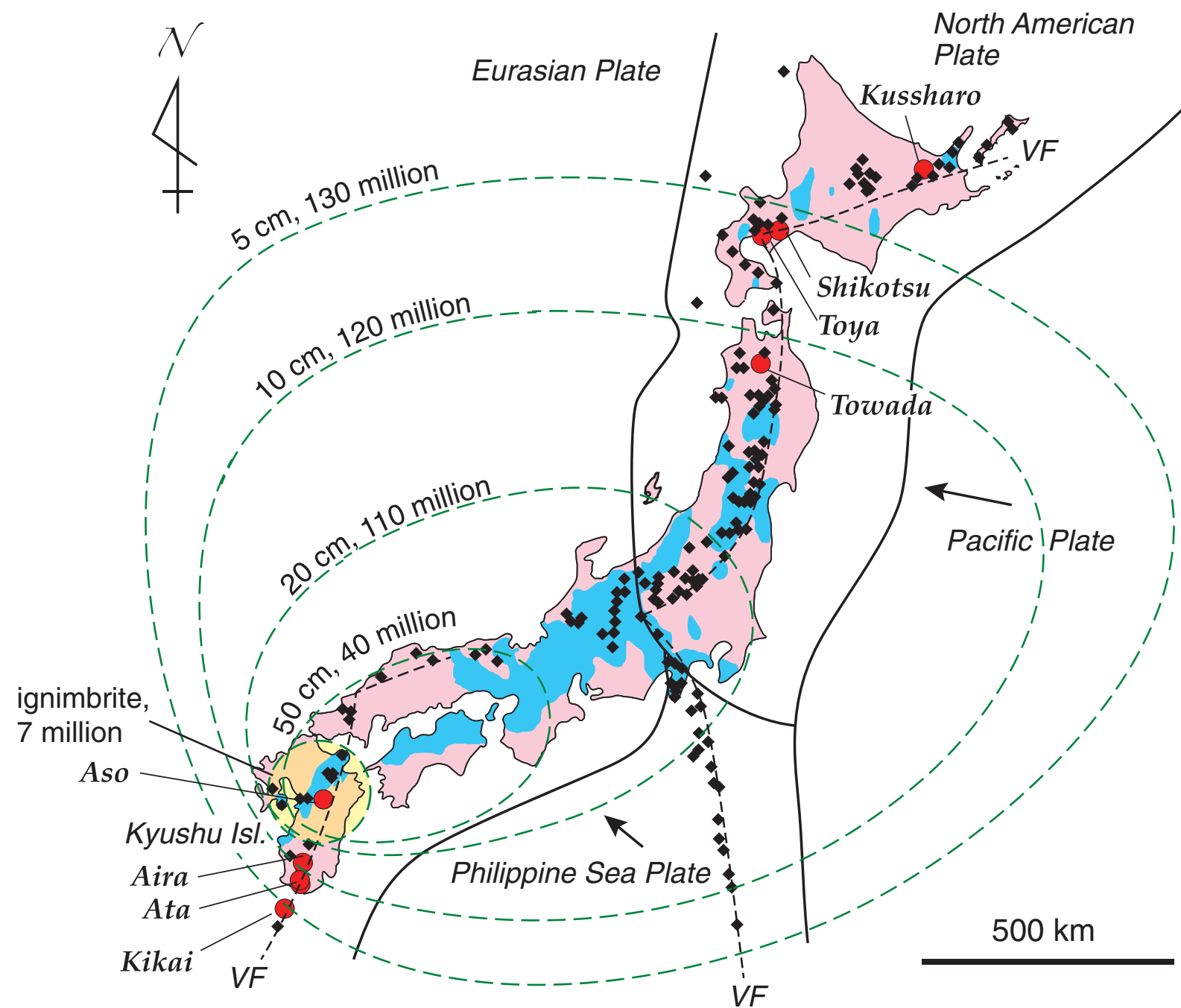

Fig. 2. Distributions of caldera-forming (red circles; $<120 \mathrm{ka}$ ) and other active (black diamonds) volcanoes in Japan. Map also shows Ignimbrite distribution and tephra isopachs for a $M=8.4$ catastrophic eruption that occurs in central Kyushu, and the number of people currently living within the areas covered by the isopachs. Caldera-forming volcanoes that caused catastrophic eruptions are located in regions of low strain rate $\left(<0.5 \times 10^{8} / \mathrm{y}\right.$, pink area; cf, regions of high strain rate beyond $0.5 \times 10^{8} / \mathrm{y}$ in blue), suggesting that low strain-rate may encourage segregation and ascent of silicic magma, and enable it to collect in large magma reservoirs. VF, volcanic front.

allow us to quantify the likelihood of future events in Japan. The best estimate for the frequency of $M \geq 7$ eruptions is between 0.10 and 0.073 events per 1000 years, based on past eruption records and probability analyses applying the Weibull distribution to the $M-F$ relationship (Table 1). Assuming an independent process for each catastrophic eruption and a constant mean occurrence rate, the occurrence of catastrophic eruptions can be described by a homogeneous Poisson distribution. ${ }^{2), 18)}$ It is then possible to derive the probability of such eruptions recurring in the near future (Table 1 ). There is 0.73 $1.0 \%$ probability of $M \geq 7$ event, and $0.25-0.26 \%$ of
$M \geq 8$ event occurring in the next hundred years. Although these probabilities seem low, it should be stressed that immediately before the 1995 Kobe Earthquake the 30-year probability of such an earthquake occurring was $0.38-7.8 \%$ (ref. 19).

In order to assess the risks associated with future catastrophic eruptions in Japan, we need to evaluate the hazards posed by past events. The Aira eruption $(M=8.4)$ that occurred at $\sim 28$ ka in Kyushu Island (Fig. 2), is used as a reference eruption, since the distribution of ignimbrite and tephra erupted is well documented. ${ }^{20), 21)}$ This eruption resulted in formation of the Aira caldera with a diameter of $20 \mathrm{~km}$. 
Table 1. Likelihood of future catastrophic eruptions in Japan arcs

\begin{tabular}{cccccccc}
\hline Magnitude & $\begin{array}{c}\text { Mass } \\
(\mathrm{kg})\end{array}$ & $\begin{array}{c}\mathrm{DRE}^{*} \\
\text { volume } \\
\left(\mathrm{km}^{3}\right)\end{array}$ & $\begin{array}{c}\text { Tephra } \\
\text { volume } \\
\left(\mathrm{km}^{3}\right)\end{array}$ & $\begin{array}{c}\text { Cumulative } \\
\text { frequency } \\
(/ \mathrm{ky})\end{array}$ & $\begin{array}{c}\text { Probability } \\
\text { in the next } \\
100 \mathrm{y}(\%)\end{array}$ & $\begin{array}{c}\text { Calculated } \\
\text { cumulative } \\
\text { frequency } \\
(/ \mathrm{ky})\end{array}$ & $\begin{array}{c}\text { Probability } \\
\text { in the next } \\
100 \mathrm{y}(\%)\end{array}$ \\
\hline 7 & $1.0 \times 10^{14}$ & 40 & 100 & 0.10 & 1.0 & 0.073 & 0.73 \\
8 & $1.0 \times 10^{15}$ & 400 & 1000 & 0.025 & 0.25 & 0.026 & 0.26 \\
\hline
\end{tabular}

${ }^{*}$ Dense rock equivalent volume calculated assuming an uniform density of $2500 \mathrm{~kg} / \mathrm{m}^{3}$.

Major pyroclastics from this eruption cover areas of $\sim 30,000 \mathrm{~km}^{2}$ (ignimbrite), $\sim 140,000 \mathrm{~km}^{2}(\geq 50 \mathrm{~cm}$ tephra isopach), $530,000 \mathrm{~km}^{2}(\geq 20 \mathrm{~cm}$ tephra isopach), $1,510,000 \mathrm{~km}^{2}$ ( $\geq 10 \mathrm{~cm}$ tephra isopach), and $2,500,000 \mathrm{~km}^{2}$ ( $\geq 5 \mathrm{~cm}$ tephra isopach). Although we are unable to identify exactly which volcano will cause such a catastrophic eruption in the future, we think it is likely to be located in central Kyushu. The reasons for this are twofold: (i) catastrophic caldera-forming eruptions have occurred repeatedly (seven times in the last $120 \mathrm{ky}$ ) in Kyushu Island, (ii) as tephra distribution is strongly influenced by the prevailing wind, which in Japan is from the west, an eruption on Kyushu would be the worst case scenario for disruption from the tephra in the most densely populated regions in Japan to the east. We provide a simple hazard map for this catastrophic eruption, including the areas of ignimbrite and tephra distribution and the population in each area (Fig. 2). Ignimbrite and ash fall thicker than $50 \mathrm{~cm}$ will cause immense disruption, leading to the areas affected being abandoned and mass migration. Currently $\sim 40$ million people live in the areas that we predict would be covered by such thick amounts of ash and ignimbrites. Where ash fall is less than $50 \mathrm{~cm}$ but thicker than $20 \mathrm{~cm}$, all utilities and transport will stop completely; we predict this would affect a further $\sim 70$ million people.

\section{Acknowledgements}

We would like to thank Steve Sparks, Koji Kiyosugi, and Yukio Hayakawa for productive discussions and Alex Nicholls for his constructive comments on the manuscript. Comments by Takeshi Hashimoto, Tak Koyaguchi, Ichio Moriya, and Yasuaki Sudo were helpful in improving the paper.

\section{References}

1) Pyle, D.M. (1995) Mass and energy budgets of explosive volcanic eruptions. Geophys. Res. Lett. 22, 563-566.
2) Mason, B.G., Pyle, D.M. and Oppenheimer, C. (2004) The size and frequency of the largest explosive eruptions on Earth. Bull. Volcanol. 66, $735-748$.

3) Christiansen, R.L. (2001) The Quaternary to Pliocene Yellowstone Plateau Volcanic Field of Wyoming, Idaho, and Montana. U. S. G. S. Prof. Paper 729-G, U. S. Geol. Surv., Denver.

4) Hildreth, W. (2007) Volcanological perspectives on Long Valley, Mammoth Mountain, and Mono Craters: several contiguous but discrete systems. J. Volcanol. Geotherm. Res. 136, 169-198.

5) Hayakawa, Y. (2013) Hayakawa's 2000-year eruption database and one-million-year tephra databases. http://www.hayakawayukio.jp/database/.

6) Deligne, N.I., Coles, S.G. and Sparks, R.S.J. (2010) Recurrence rates of large explosive volcanic eruptions. J. Geophys. Res. 115, B06203.

7) Embrechts, P., Kluppelberg, C. and Mikosch, T. (1997) Modelling Extremal Events for Insurance and Finance. Springer, Berlin Heidelberg New York.

8) Sparks, R.S.J. and Sigurdsson, H. (1977) Magma mixing: A mechanism for triggering acid explosive eruptions. Nature 267, 315-318.

9) Caricchi, L., Annen, C., Blundy, J., Simpson, G. and Pinel, V. (2014) Frequency and magnitude of volcanic eruptions controlled by magma injection and buoyancy. Nat. Geosci. 7, 126-130.

10) Malfait, W.J., Seifert, R., Petitgirard, S., Perrillat, J.-P., Mezouar, M., Ota, T., Nakamura, E., Lerch, P. and Sanchez-Valle, C. (2014) Supervolcano eruptions driven by melt buoyancy in large silicic magma chambers. Nat. Geosci. 7, 122-125.

11) Hildreth, W. (1981) Gradients in silicic magma chambers: implications for lithospheric magmatism. J. Geophys. Res. 86, 10153-10192.

12) Annen, C., Blundy, J.D. and Sparks, R.S.J. (2006) The genesis of intermediate and silicic magmas in deep crustal hot zones. J. Petrol. 47, 505-539.

13) Tatsumi, Y., Takahashi, T., Hirahara, Y., Chang, Q., Miyazaki, T., Kimura, J.-I., Ban, M. and Sakayori, A. (2008) New insights into andesite genesis: the role of mantle-derived calc-alkalic and crust-derived tholeiitic melts in magma differentiation beneath Zao Volcano, NE Japan. J. Petrol. 49, 1971-2008.

14) Takahashi, T., Hirahara, Y., Miyazaki, T., Senda, R., Chang, Q., Kimura, J.-I. and Tatsumi, Y. 
(2013) Primary magmas at the volcanic front of the NE Japan arc: coeval eruption of crustal low-K tholeiitic and mantle-derived medium-K calc-alkaline basalts at Azuma Volcano. J. Petrol. 54, 103-148.

15) Nakamura, K. and Uyeda, S. (1980) Stress gradient in arc-back arc regions and plate subduction. J. Geophys. Res. 85, 6419-6428.

16) Nohara, T., Koriya, Y. and Imaizumi, T. (2000) An estimation of the crustal strain rate using the active fault GIS data. Active Fault Res. 19, 23-32.

17) Vigneresse, J.L. (2006) Granitic batholiths: from pervasive and continuous melting in the lower crust to discontinuous and spaced plutonism in the upper crust. Trans. R. Soc. Edinb. Earth Sci. 97, 311-324.
18) McBirney, A.R., Serva, L., Guerra, M. and Connor, C.R. (2003) Volcanic and seismic hazards at a proposed nuclear power site in central Java. J. Volcanol. Geotherm. Res. 126, 11-30.

19) The headquarters for Earthquake Research Promotion (2001) Methods of evaluation of the long-term earthquake occurrence probability, MEXT, Tokyo.

20) Aramaki, S. (1984) Formation of the Aira Caldera, southern Kyushu, 22,000 years ago. J. Geophys. Res. 89, 8485-8501.

21) Machida, K. (1999) The stratigraphy, chronology and distribution of distal marker-tephras in and around Japan. Glob. Planet. Change 21, 71-94.

(Received July 16, 2014; accepted Sep. 22, 2014) 